\title{
Living in a bubble? Toward a unified bubble theory
}

\author{
Yuval Nov ${ }^{\mathrm{a}} *$ and Oded Nov \\ ${ }^{a}$ Department of Statistics, University of Haifa, Haifa, Israel; ${ }^{b}$ Department of Management, \\ Polytechnic University, New York, NY, USA
}

(Received 9 November 2006; final version received 8 February 2008)

\begin{abstract}
We generalise the notion of a bubble beyond the financial domain, by showing how a single social mechanism, based on an information feedback-loop, explains both financial bubbles and other seemingly disparate social phenomena, such as the recognition of academic articles, website popularity, and the spread of rumours.

We discuss examples of phenomena explained by this bubble mechanism, as well as other phenomena that exhibit certain bubble characteristics, yet are not bubbles according to our model. Finally, we present mathematical mechanisms for two phenomena that conform with our model, and show by computer simulation how they exhibit bubble behaviour.
\end{abstract}

Keywords: bubble; feedback loop; external value; driving value; fundamental value

\section{Introduction}

The term bubble has been used in the context of asset prices in various ways. Its definition in The New Palgrave: A Dictionary of Economics (Eatwell et al. 1987) is

A sharp rise in the price of an asset or a range of assets in a continuous process, with the initial rise generating expectations of further rises and attracting new buyers - generally speculators interested in profits from trading in the asset rather than its use or earnings capacity.

Others (Rosser 2000, Garber 2000, Siegel 2001) stress that bubbles occur when the price of an asset increases in a way that is incommensurate with the asset's fundamentals, such as cash flows or price/earning ratios. Shiller (2000) adds that such an increase is unsustainable, and is driven by a feedback loop that both reflects and generates expectations for further increases in price; he also discusses behavioural dynamics (e.g., herd behaviour) underlying bubbles, and notes that bubbles may resolve in a sudden burst, or in a slow decline of prices.

Bubbles are primarily viewed as a financial phenomenon; an exception is Gori and Witten's (2005) discussion of web visibility bubbles formed by search engines, but they use the term 'bubble' in a different sense from ours.

Feedback loops, a fundamental notion in system theory, emerge in fields as diverse as organisational theory, electrical engineering, epidemiology, cognitive psychology, and meteorology, and are well studied mathematically (Luenberger 1979). In the social context, feedback loops were used to explain non-financial 'hypes', such as the advancement of scientific theories (Sterman and Wittenberg 1999).

*Corresponding author. Email: yuval@stat.haifa.ac.il

ISSN 0308-1079 print/ISSN 1563-5104 online

(C) 2008 Taylor \& Francis

DOI: $10.1080 / 03081070802037696$

http://www.informaworld.com 
Another key component of system theory, as laid out by Polderman and Willems (1998), is that of a system's behaviour, made precise by the behavioural equations which govern the evolution trajectory of a dynamic system. In the mathematical system theory literature, the term 'behaviour' has been long stripped of its everyday sense, yet we shall denote with it a certain component of a mechanism that drives a system's dynamics, which indeed corresponds to human behaviour.

In this work, we generalise the notion of bubbles beyond the financial domain. We present an information feedback loop model that explains how the 'value' of an object may increase in a way that is unexplainable by its fundamentals, and show how this model applies to various non-financial social phenomena.

\section{Model definition}

To illustrate how the concept of a bubble may be generalised beyond the financial context, we first review a famous bubble - the Dutch tulip craze of the 17th century. Newly introduced tulips became coveted by Holland's rich during the early 1600s; tulip bulb prices increased steadily, and by the 1620s and 1630s some single tulip bulbs were selling for prices exceeding the annual income of a wealthy merchant. A futures market for bulbs was formed, speculators sold bulbs at a 20-fold markup within one month of purchase, and people were selling their homes and using their savings to finance tulip trade plans. The market started collapsing in 1637, after a buyer refused to pay the price he had offered in an auction; panic spread quickly, and within a few weeks, prices plummeted to a fraction of their original values (Dash 2000).

Using the tulip example, we now introduce a framework for defining and analysing bubbles. At the centre of the bubble phenomenon lies an object, relative to which people behave. In the tulip example, the tulip bulbs are the object, and the behaviour is their buying and selling. The object has an attribute we call the external value, which is measurable and observable by everybody (at least in principle), and about which information can be communicated; changes in the external value of the object are a direct result of people's behaviour. In the tulip example, the external value is the market price of the tulip bulbs, which is indeed driven by people's trade (i.e., by their behaviour).

The object has another attribute, which we call the driving value; this value is subjective or uncertain, and directly drives people's behaviour. The tulips' driving value is the profit people believed they could make by trading bulbs, or more precisely, a subjective probability distribution over this profit: people did not buy tulip bulbs in order to enjoy the beauty of the flowers sprouting from them; they bought them to make money.

In this tulip example, both the external value (market price) and the driving value (future profit) have nothing to do with the tulips themselves, and in particular, neither of them captures what one might naïvely claim to be the 'basic' nor 'true' value of tulips: the joy they bring people while looking at them. We term this value the fundamental value of the object. Fundamental values are often attributed to financial assets, and their elusive nature is recognised in the finance literature (Shiller 2003). We shall use this term in a broad sense to denote any desirable intrinsic quality of an object; however, the mechanism presented below for the evolution of bubbles does not depend on it.

Now suppose that the object's external value tends to influence positively its driving value (i.e., an increase in the external value tends to generate an increase in the driving value, and similarly for a decrease). This is certainly the case in the tulip example: increasing market prices (external value) convince people that handsome profits can be made (an increase in driving value), and decreasing market prices spoil the attractiveness of bulbs as an investment. 


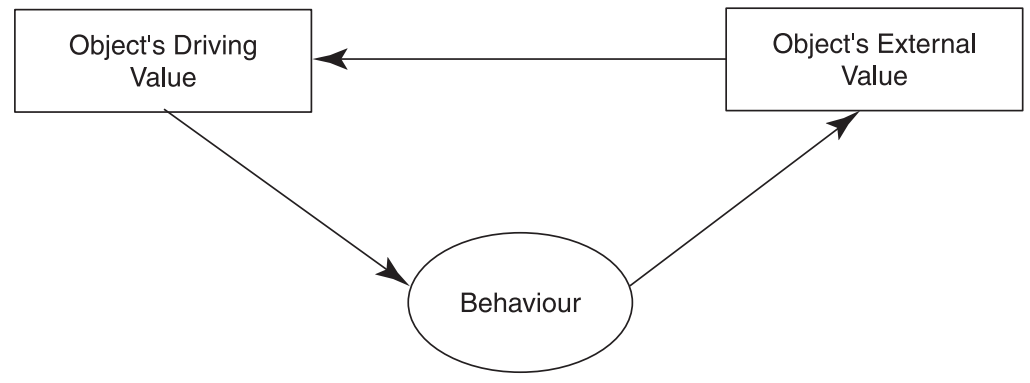

Figure 1. The information feedback loop generating bubbles.

A bubble develops when a positive feedback loop is formed between an object's external and driving values, mediated by people's behaviour and accompanied by little or no change to its fundamental value (see Figure 1). The tulip example definitely demonstrated this pattern: people's demand for tulip bulbs (behaviour) caused the bulb prices (external value) to soar; the growing prices caused the bulbs to seem more attractive as an investment (driving value), generating further demand, and so on. Crucially, while this loop was taking place, the pleasure the tulips gave people while looking at them (fundamental value) was not changing.

It is easy to see how this framework applies to other well-known financial bubbles, such as stock market bubbles and real estate bubbles. In both cases, the external value is the market price of the object (the object being a stock or a real estate asset), behaviour is trade in the object, and the driving value is the profit people believe they will realise by this trade. Here again, increasing external values (market prices) are typically not accompanied by a significant change in the object's fundamental values - the actual net profits of firms whose stock prices soared, in the case of a stock market bubble, and the quality of life in the city in which a real estate bubble is forming.

Obviously, the feedback loop described above is not always at work, as bubbles are the exception rather than the rule. We develop here a model that explains how existing bubbles grow, but do not attempt to specify what triggers this growth and how bubbles resolve.

\section{Non-financial bubbles}

Our main goal is to show how the framework developed in the previous section applies also to social phenomena outside the financial domain. We now present four examples illustrating this point.

\subsection{Academic citations}

Consider an issue close to home - academic citations. The object in this case is an academic article, and people's behaviour is their choice whether or not to cite it in their own published work. The external value of the article at time $t$ may be taken to be the number of times it was cited during, say, the year prior to $t$, which is indeed a direct result of people's behaviour. The driving value is people's beliefs about the article's quality, novelty, breadth, or relevance - a scholar cites an article primarily because he or she thinks it is good. Clearly, these beliefs about how good the article is are influenced, in turn, by how well-cited it is. Again, we get the feedback loop summarised in Figure 1. 
An important point here is that nothing in the article itself - and in particular, in its true quality, novelty, etc., which make its fundamental value - changes while the loop is feeding back. The article is not more or less true, better predicting, or otherwise of scholarly value, as the number of its citations increases.

Just as in the financial case, this is certainly not to say that bubble behaviour underlies the recognition gained by all, or even most, academic works. Rather, we claim that our model may explain the popularity of some works. This note applies also to the rest of the examples in this section.

\subsection{Website ranking}

Another non-financial bubble may form around the popularity of internet websites. The object here is a webpage $P$ that contains information about a certain term (e.g., a book, a person, a news item or a software); the external value of $P$ is its ranking in search engine results, when searching for the term. In today's technology, this ranking is determined to a large extent by the number of other webpages that link to $P$, so people's behaviour namely, their choice whether or not to link to $P$ from their own webpages - determines $P$ 's external value. Why do people choose to link to a certain webpage, rather than to another one? Often because they believe that the page contains relevant and complete information about the term, so such a belief is the driving value of $P$. However, people often form this belief simply by searching for the term, and observing which webpage is ranked highest in the results (i.e., the driving value is a direct consequence of the external value), so once again, the feedback loop depicted in Figure 1 is at work.

A mirror image of this loop was recently discussed in the literature (Pandey et al. 2005), though using different terminology from ours: high-quality websites (i.e., websites having high fundamental value) may fail to get ranked highly (i.e., have low external values), since their initial low rankings prevents other website owners from visiting and linking to them.

\subsection{Rumours}

Another process that fits our bubble model is the spread of rumours. The object here is a piece of information, and its fundamental value may be taken to be its truthfulness; people's behaviour is spreading the information to people who haven't heard it yet, the external value is the rumour's prevalence, and the driving value, at least to some extent, is the degree to which people believe the information is true.

The feedback loop works as follows: people's behaviour (spreading the rumour) is influenced by the driving value (the extent to which they believe the rumour is true), and this behaviour increases the rumour's external value (its prevalence). The external value, in turn, tends to increase the driving value, as people's beliefs about the truthfulness of the rumour are influenced by the prevalence of the rumour, following the "where there's smoke there's fire" idea. Just as in the previous examples, the above feedback loop increases the external value of the rumour, without any change to its fundamental value namely, its truthfulness.

\subsection{Management fads}

A fourth example of a non-financial bubble is the proliferation of management fads. The object here is a management technique, and its external value is its prevalence - the 
number of organisations that have adopted it. Behaviour in this case is executives' decision whether or not to adopt the technique, and its influence on the external value is clear. The driving value may be the executives' belief about how effective (i.e., contributing to profit, morale, etc.) is the technique, or it may be the amount of pressure they feel to be seen by their superiors or shareholders as 'doing the right thing' - adopting the hyped technique. In either case, the driving value is heavily influenced by the external value, so once again we have the feedback loop, which may inflate the external value significantly even though the fundamental value of the technique - its true effectiveness may be small or non-existent.

Other phenomena that often fit our bubble model, in addition to the four analysed above, are quack medicine, and the reputation of companies, people, or products.

\section{Similar characteristics, yet not a bubble}

The mechanism described above resembles - but is not identical to - other rapid growth phenomena driven by human behaviour. We now present and discuss three of these, and explain why they are not bubbles, according to our definition.

\subsection{Network effect}

The term 'network effect' (or 'network externalities') describes a situation in which the utility a user derives from consuming a good increases with the number of others consuming that good (Katz and Shapiro 1985). The good is usually a technology, such as email or an operating system, and the rapid growth in the use of such a technology shares some similarities with bubbles. As an example, we take the use of email in the early days of the internet. People's behaviour here was their subscribing for the first time to an email service, so we may take the number of email subscribers as the external value. People subscribed to an email service when they realised that email will be useful for them, so the driving value of email is its perceived usefulness. Clearly, the more email subscribers there are, the more useful email becomes to everybody, and a feedback loop is formed between prevalence and usefulness.

The crucial point is that in this case the fundamental value - the true usefulness of email - and the driving value coincide: when more people start using email, email is becoming more useful, so there is no growing gap between the fundamental and the external values. Thus, network effect phenomena are not bubbles.

\subsection{Fashion}

Every year, the sales of certain new, fashionable apparel peak and then decline; on a larger time scale, phenomena such as the Hula Hoop craze of the 1950s and the Rubik Cube craze of the early 1980s exhibit similar characteristics. Even though the evolution of these phenomena may involve a feedback loop, they are not bubbles, according to our definition. We take the fundamental value of a fashionable garment to be the joy or social respect its owner derives from wearing it, and not the garment's capacity to protect from the weather, etc. This fundamental value is directly influenced (possibly in a complex way) by the number and identity of the other people who wear the garment, which may be taken to be the external value. Thus, there is no growing gap between the two values, in contrast to our bubble model. 


\subsection{Grade inflation}

The average student grades in US universities and colleges were reported to increase slowly but steadily in the last 40 years (Rojstaczer 2003), though the existence of this trend is controversial (Kohn 2002). Even if this phenomenon is real, it does not conform to our bubble model: grade inflation may be viewed as merely a 'change of units', which makes the resolution of the grade picture coarser, but can be reinterpreted in a way that reflects no increase. Moreover, one may argue that grade inflation involves no feedback loop professors who choose to grade their students' work more leniently in no way set, by doing so, expectations for even further leniency in the future.

\section{Numerical examples}

We now show, through two examples, how the qualitative ideas described in Section 2 may be translated into quantitative models. The exact details of the translation depend on the type of bubble discussed, but the heart of the matter - the mechanism through which bubbles grow - is the same.

\subsection{A financial bubble}

As a first example, consider a financial object such as a stock index. The external value of the object at time $t, E_{t}$, is its price, and the driving value at time $t, D_{t}$, is the profit one hopes to realise by buying and selling the asset. The object's fundamental value is set to be a constant $f$. Normally, when the asset is overpriced (i.e., $E_{t}>f$ ) it becomes less attractive as an investment, and the "next" driving value, $D_{t+1}$, becomes low; the opposite happens when the asset is underpriced. The external value, in turn, is influenced by the driving value: when the asset is desirable (i.e., $D_{t}$ is high), its price $E_{t}$ increases, and vice versa. These are the dynamics microeconomic theory would predict, and they have nothing to do with bubbles.

However, when the external price increases steadily across a sufficiently long period of time (say, throughout $k$ consecutive periods), investors may switch to the behaviour described in Section 2: increasing prices $\left(E_{t}\right)$ will tend to increase the driving value $\left(D_{t}\right)$, and vice versa. We get a bubble that keeps growing as long as the external value increases, and bursts as soon as the external value decreases.

More precisely, we model the driving and external values as

$$
D_{t}=\left\{\begin{array}{cl}
D_{t-1}+\alpha\left(E_{t-1}-E_{t-2}\right)+\varepsilon_{t}^{D} & \text { if } E_{t-k-1}<E_{t-k}<\ldots<E_{t-1} \\
\beta\left(f-E_{t-1}\right)+\varepsilon_{t}^{D} & \text { otherwise }
\end{array}\right.
$$

and

$$
E_{t}=\left\{\begin{array}{cl}
E_{t-1}+\gamma\left(D_{t}-D_{t-1}\right)+\varepsilon_{t}^{E} & \text { if } E_{t-k-1}<E_{t-k}<\ldots<E_{t-1} \\
\delta D_{t}+\varepsilon_{t}^{E} & \text { otherwise, }
\end{array}\right.
$$

where $\alpha, \beta, \gamma$ and $\delta$ are positive constants, and the error terms $\left\{\varepsilon_{t}^{D}\right\}$ and $\left\{\varepsilon_{t}^{E}\right\}$ are independent sequences of independent, zero-mean normal random variables.

A typical sample path of this process, simulated on a computer, is shown in Figure 2 (parameters are $f=100, \alpha=\gamma=0.9, \beta=\delta=0.5$, $\operatorname{Var}\left(\varepsilon_{t}\right)=4$ and $k=4$ ). The trajectory of the object's price indeed exhibits bubble characteristics: occasional growth spurts, which are unrelated to the object's fundamental value. 


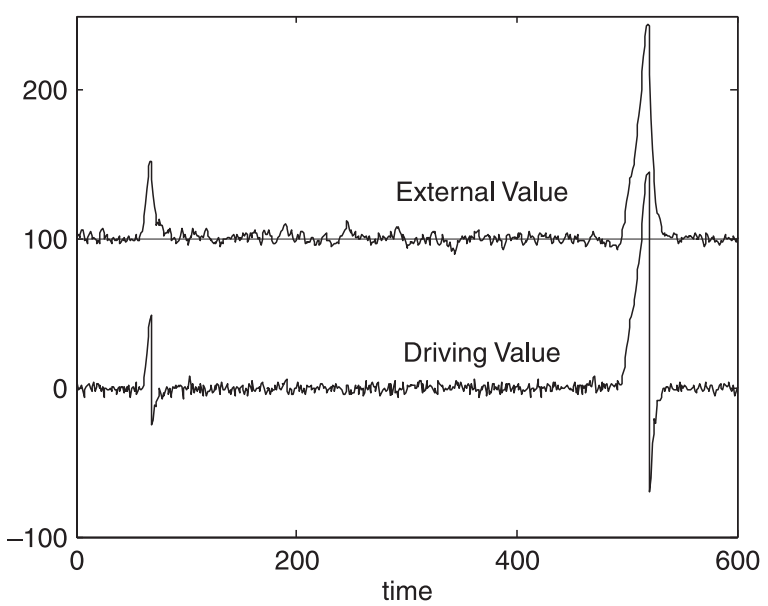

Figure 2. Financial bubble simulation. Fundamental value is the constant 100 .

\subsection{Academic citations}

Consider a research community of $M$ researchers, and an academic article. At each time period, each of the researchers may or may not cite the article in his or her own published work (a researcher cannot cite the paper more than once in a time period). Let $C_{j, t}$ be the indicator random variable that indicates whether researcher $j$ cites the article at period $t$, and define the external value at time $t$ to be the fraction of the researchers who cite the paper, that is, $E_{t}=(1 / M) \sum_{j=1}^{M} C_{j, t}$.

The probability that researcher $j$ cites the paper at time $t$ is $P\left(C_{j, t}=1\right)=g\left(D_{j, t}\right)$, where $g$ is an increasing function, and $D_{j, t}$ is researcher $j$ 's driving value at time $t$, which reflects his or her belief about the article's quality or relevance. The individual driving values incorporate both the previous period's driving values and the previous period's external values: $D_{j, t}=\lambda D_{j, t-1}+(1-\lambda) E_{t-1}$, where $\lambda$ is a constant in the interval $[0,1)$.

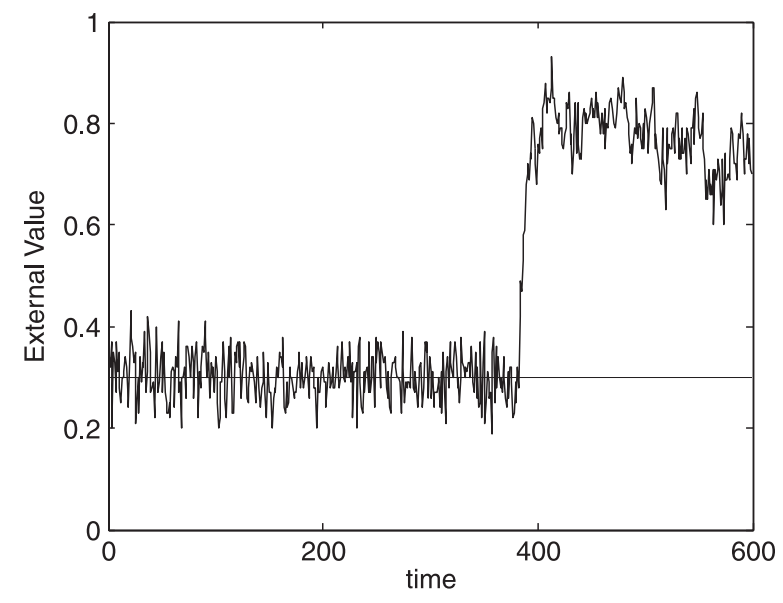

Figure 3. Citation bubble simulation. Fundamental value is the constant 0.3 ; driving value follows the external value very closely, and is not shown. 
A sample path of the external value process, simulated on a computer, is shown in Figure 3 (parameters are $M=100$ and $\lambda=0.3$; the function $g$ is defined by $g(d)=0.3$ if $d<0.42$, and $g(d)=0.17+0.78 d$ if $d \geq 0.42$ ). The driving value follows the external value closely, and is therefore not shown in Figure 3. The trajectory of the external value grows at a certain point significantly, without any changes in the true scholarly value of the article itself. Such a bubble, once formed, may disappear due to forces not included in the above model (preference to cite recent, rather than dated, articles; emergence of a new, clearly superior, article; discovery of errors in the original article; etc.), or may last for a long period of time, as one might say is the case with some academic works.

\section{Conclusion}

The contribution of this work is in generalizing and exploring the notion of a bubble beyond the financial domain. According to this view, bubbles are a general social phenomenon, of which financial bubbles are only one manifestation. We develop a general model that is applicable to objects as disparate as academic articles, websites, rumours, managerial fads, and financial assets, which explains how the 'value' of these objects may increase, through a certain feedback loop, even when the objects' fundamentals are unchanged.

This bubble framework allows us to draw a parallel between two questionable practices: a certain variant of the 'pump and dump' stock trading strategy, and mutualcitation agreements. In the former, an investor buys large quantities of a stock in order to increase artificially its price, thus creating a 'buzz' around it, which will draw unsuspecting investors to buy the stock and increase its price even further (Allen and Gale 1992). In the latter, two or more academic scholars agree to cite each others' publications, thus increasing the publications' perceived merit (Masum and Zhang 2004). Using the bubble terminology presented in this article, it is easy to see the similarity between these seemingly disparate phenomena: In both cases, people artificially increase the external value of an object (the price, when the object is a stock, or the number of citations, when it is an academic article), in the hope that this will increase also the driving value of the object (expectations for profit, or perceived merit of the article), thus triggering the bubble feedback loop. This feedback loop will keep the external value rising, without any change to the object itself, and in particular, to its fundamental value.

Bubbles, we argue, are social phenomena, prevalent in disparate domains. In this article, we formalise and explore this idea, hoping it will constitute as a first step toward a unified bubble theory.

\section{Notes on contributors}

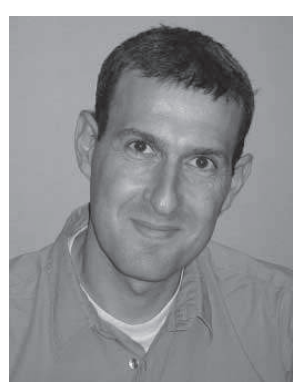

Oded Nov is an Assistant Professor of Management at Polytechnic University, New York. He received his PhD from the University of Cambridge, UK. His research interests include behavioural and organisational aspects of information systems, knowledge management and technology management. 


\section{References}

Allen, F. and Gale, D., 1992. Stock price manipulation. Review of financial studies, 5, 503-529.

Dash, M., 2000. Tulipomania: The story of the world's most coveted flower and the extraordinary passions it aroused. New York: Crown.

Eatwell, J., Milgate, M. and Newman, P., eds, 1987. The New Palgrave: A dictionary of economics. New York: Stockton Press, 281.

Garber, P., 2000. Famous first bubbles. Cambridge: MIT Press.

Gori, M. and Witten, I., 2005. The bubble of web visibility. Communications of the ACM, 48, 115-117.

Katz, M. and Shapiro, C., 1985. Network externalities, competition, and compatibility. American economic review, 75, 424-440.

Kohn, A., 2002. The dangerous myth of grade inflation. The chronicle of higher education, 49, B7.

Luenberger, D., 1979. Introduction to dynamic systems: Theory, models, and applications. New York: Wiley.

Masum, H. and Zhang, Y., 2004. Manifesto for the reputation society. Available from: firstmonday.org/issues/ issue9_7/masum/index.html [Accessed 8 Feb 2008].

Pandey, A., Roy, S., Olston, C., Cho, J. and Chakrabarti, S., 2005. Shuffling a stacked deck: The case for partially randomised ranking of search engine results. Proceedings of the 31st VLDB Conference, 30 August -2 September 2005, Trondheim, Norway. New York: ACM, 781-792.

Polderman, J. and Willems, J., 1998. Introduction to mathematical systems theory: A behavioral approach. New York: Springer-Verlag.

Rojstaczer, S., 2003. Where all grades are above average. Washington Post, January 28 2003, A21.

Rosser, J., 2000. From catastrophe to chaos: A general theory of economic discontinuities. Boston: Kluwer.

Shiller, R., 2000. Irrational exuberance. Princeton: Princeton University Press.

Shiller, R., 2003. From efficient markets theory to behavioural finance. Journal of economic perspectives, $17,83-104$.

Siegel, J., 2003. What is an asset price bubble? An operational definition. European financial management, $9,11-24$.

Sterman, J. and Wittenberg, J., 1999. Path dependence, competition and succession in the dynamics of scientific revolution. Organisation science, 10, 322-341. 